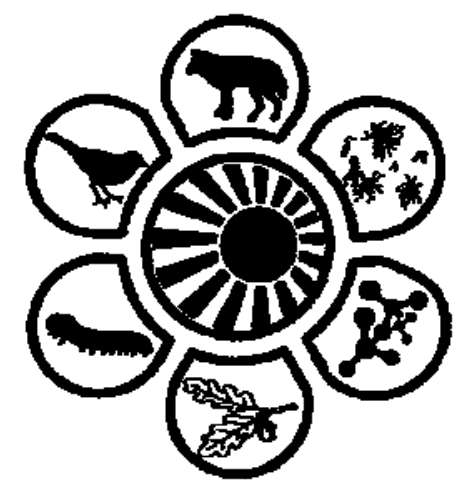

Вісник Дніпропетровського університету. Біологія, екологія.

Vìsnik Dnìpropetrovs'kogo unìversitetu. Seriâ Bìologiâ, ekologiâ

Visnyk of Dnipropetrovsk University. Biology, ecology.

Vìsn. Dnìpropetr. Unìv. Ser. Bìol. Ekol. 2014. 22(1), 53-59.

doi:10.15421/011407

ISSN 2310-0842 print

ISSN 2312-301X online

www.ecology.dp.ua

УДК 577.3+57.043

\title{
Кислотно-гемолитическая устойчивость эритроцитов напряженного эритропоэза в условиях низкочастотной вибрации
}

\author{
О.И. Доценко
}

Донецкий наџиональный университет, Донеик, Украина

Исследовано 14-дневное влияние вибрации с частотами 8, 16, 24 и 32 Гц, амплитудой $0,8 \pm 0,12$ мм на кислотную резистентность эритроцитов мышей. Вибрация с частотами 8, 16 и 24 Гц вызывает напряженный эритропоэз. Высокая активность стрессреализующих механизмов приводит к падению общего содержания эритроцитов в крови, снижению доли «старых», низкостойких эритроцитов и общему повышению их устойчивости к кислотному гемолизу. Вибрация с частотой 32 Гц блокирует эритропоэз, следствием чего является быстрое истощение резерва зрелых эритроцитов и снижение их кислотной устойчивости.

Ключевые слова: низкочастотная вибрация; кислотная резистентность; эритроциты; эритропоэз

\section{Acid-hemolytic stability of erythrocytes of intense erythropoiesis under conditions of low-frequency vibration}

\author{
O.I. Dotsenko
}

\section{Donetsk National University, Donetsk, Ukraine}

This paper deals with the peculiarities of functioning of murine erythron system under vibrational stress on the basis of experimental data about erythrocytes acid resistance. Experiments were made on the outbred male mice at about one age and weight that were maintained in vivarium conditions on usual diet. Animals were divided into 5 groups. Animals of 1-4 groups were exposed to daily thirty-minute vibration at frequencies of $8,16,24$ and $32 \mathrm{~Hz}$ respectively, with amplitude of $0.8 \pm 0.12 \mathrm{~mm}$ during 14 days. Animal exposure to vibration was provided by the electromechanical converter connected to the generator of low frequency signals. The fifth group of animals was not exposed to vibration and it was used as a control. Kinetic dependences of acid hemolysis of erythrocytes was registered daily, from the 1st to the 5th day, and further at the 7th, 9th and 14th days of experiment. Blood for analysis was taken from tail veins in 15-20 min after stopping of vibration. As the basic indicators characterizing resistance of erythrocytes to the hemolytic agent influence we used the hemolysis rate constant, i.e. the value inverse to cell half-life time. For analysis of acid erythrograms we also used such indicators as hemolysis duration, maximum erythrogram's time and width of the interval of erythrocyte group dominating in the population. We processed the results of research statistically. The study showed that acid resistance of erythrocytes decreased during the first five days of vibration influence at frequencies of 8-16 Hz. Besides, erythrocytes were divided into fractions that indicated the erythrocytes aging and strengthening of the population heterogeneity. On the fifth day of $16 \mathrm{~Hz}$ influence the emission of reticulocytes was recorded. At $8 \mathrm{~Hz}$ influence these processes were registered on the 7th day of the experiment. During the subsequent days the hemolysis curves were slightly displaced in relation to the control. Increase in hemolysis time and forms of erythrograms suggested the existence of erythrocytes fraction with increased resistance to the haemolytic factor. High activity of stress-induced mechanisms led to the drop in the general erythrocytes content in blood, and to the decrease in the share of low-resistant "old" erythrocytes and general increase in erythrocytes stability to the acid hemolysis. At $24 \mathrm{~Hz}$ vibration influence we observed similar processes; however, during the second week of action the content of "old" erythrocytes in murine blood was much higher, compared with "young" cells. Strengthening of erythrocytes heterogeneity was observed with the shift on the erythrograms to the left, emergence of several maxima, and reduction of half-life time of the cells. However, the hemolysis termination time was not reduced. At $32 \mathrm{~Hz}$ vibration the erythropoesis was not observed within 14 days of the experiment. Stress-induced disorder of the hemopoesis and cellular composition of peripheral blood were revealed and expressed in erythropoesis suppression, devastation of the "old" erythrocytes' reserve, and decrease in their acid resistance. The consequence of these processes can be hypoxia of cells and tissues, which is one of the mechanisms of organs stress injuries.

Keywords: low frequency vibration; acid resistance; erythrocytes; erythropoesis

Донеикий начиональный университет, ул. Щорса, 46, Донеик, 83050, Украина.

Donetsk National University, vul. Shersa, 46, Donetsk, 83050, Ukraine.

Tel.:+38-093-724-66-10.E-mail:dots_don@ukr.net 


\section{Введение}

Вибрация является хроническим стрессирующим фактором, вызывающим в организме человека многочисленные изменения и повреждения. В результате действия вибрации отмечают изменения окислительного и энергетического метаболизма (Kapustnik and Polyakova, 2005; Antoshina and Pavlovskay, 2009; Hughes et al., 2009; Vorobieva and Shabanov, 2012), иммунного статуса (Bobrova et al., 2002; Bodyenkova and Lizaryv, 2005), peoлогических свойств крови (Ziegler et al., 2005; Antoshina et al., 2009; Pattnaik et al., 2012), проницаемости мембран клеток (Vorobieva and Shabanov, 2010), дистрофических поражений мышечной и костной тканей (Sauni et al., 2009; Stoyneva and Dermendjiev, 2010; Heaver at al., 2011; Krajnak et al., 2012), минерального дисбаланса (Damijan, 2005; Kapustnik and Polyakova, 2005), нарушений липидного обмена, состояния гормональной системы (Bodyenkova and Lizaryv, 2005). На основании наших исследований и анализа данных литературы (Bobrova et al., 2002; Dotsenko et al., 2010) можно заключить, что реакция организма на вибрационное воздействие является неспецифичной. В многочисленных работах описаны закономерности неспецифической реакции кроветворных органов на действие различных стрессоров, которые проявляются в развитии эритропоэза (Paulson et al., 2011; Vemula et al., 2012; Dzierzak and Philipsen, 2013).

В числе интегральных характеристик, дающих представление о системных сдвигах в организме, может оказаться один из параметров системы эритрона, лежащий в основе гемолитической стойкости его клеток и определяемый методом кислотных эритрограмм. Этот метод был разработан в свое время как способ гематологических исследований для изучения изменений свойств эритроцитов при гемобластозах, анемиях и интоксикациях с поражением системы красной крови (Leonova, 1987). С его помощью оценивали гетерогенность эритроцитарной популяции в зависимости от возраста, поскольку кислотная стойкость эритроцитов способна выступать, помимо всего, и как функция возраста эритроцитарной клетки.

Работы, в которых метод кислотных эритрограмм применялся бы для динамической оценки состояния организма, находящегося в состоянии стресса, малочисленны. Однако показано, что этот метод может быть использован для изучения специфических гематологических и неспецифических общеорганизменных закономерностей острого стресса в раннем постагрессивном периоде (Mikhailis, $2009,2010)$. Комплексное изучение влияния стресса на кроветворение и клеточный состав периферической крови имеет большое значение в понимании механизмов адаптации организма к стрессорным повреждениям. В связи с вышеизложенным, цель работы состояла в изучении особенностей функционирования системы эритрона мышей, находящихся в условиях вибрационного стресса.

\section{Материал и методы исследований}

Опыты проведены на белых беспородных мышах приблизительно одного возраста и массы, содержащихся в условиях вивария на обычном рационе. Животные были разделены на пять групп. Животные 1-4-й групп подвергались ежедневной 30-минутной вибрации частотами $8,16,24$ и 32 Гц, амплитудой $0,8 \pm 0,12$ мм (интенсивность вибрации 78,7-97,2 Дб) в течение 14 дней. Вибрацию животных осуществляли с помощью электромеханического преобразователя, подключенного к генератору сигналов низких частот. Пятая группа животных не подвергалась вибрации и использовалась в качестве контроля.

Кровь для анализа брали через некоторое время после окончания вибрации из хвостовых вен и использовали для изучения кинетики кислотного $(0,004 \mathrm{M} \mathrm{HCl})$ гемолиза. Изучение динамики кислотного гемолиза проводили на длине волны 650 нм (длина волны, при которой оптическая плотность образцов зависит от светорассеяния эритромассы). Измерения оптической плотности взвеси эритроцитов после добавления равного количества гемолитика проводили с временным интервалом 1 с в автоматическом режиме. Измерение светопоглощения вели до получения совпадающих показаний оптической плотности, т.е. до завершения гемолиза (Dotsenko and Mishenko, 2011).

По спектрам поглощения гемолиза рассчитывали первые производные спектров (эритрограммы), которые использовали для определения константы скорости гемолиза $\left(k_{t_{1} / 2}\right)$ - величины, обратной времени полураспада клеток $\left(t_{1 / 2}\right)$. Для анализа кислотных эритрограмм также использовали такие показатели как продолжительность гемолиза, время, соответствующее максимумам эритрограммы, ширина интервала доминирующей группы эритроцитов в популяции.

Статистическую обработку и графическое отображение результатов осуществляли с использованием стандартных программ Excel и Statistica.

\section{Результаты и их обсуждение}

Характеристика функциональной полноценности клеток красной крови как интегрального показателя состояния организма имеет большое прогностическое значение. Совокупность физико-химических свойств мембран эритроцитов определяет их устойчивость к действию неблагоприятных факторов. В связи с этим показатели устойчивости эритроцитов широко применяются в экспериментальной медицине в целях характеристики их функционального состояния. Нефракционированные эритроциты являются совокупностью клеток разной степени зрелости и функциональной активности, время пребывания которых в крови неодинаково. В течение всей жизни эритроцита в сосудистом русле его стойкость уменьшается с возрастом. Наиболее молодые эритроциты обладают наибольшей стойкостью и занимают на эритрограмме правое положение. Процессы старения сопровождаются постоянным снижением их стойкости, что на эритрограмме отражается смещением влево. К концу жизни эритроцита его стойкость снижается до минимального значения, с которой он покидает сосудистое русло (Leonova, 1987). Таким образом, стой- 
кость эритроцитарных мембран является важнейшей величиной, связанной с физиологическим состоянием и возрастом эритроцитов.

Экспериментальные данные по изучению кислотной резистентности эритроцитов показаны на рисунках 1-4. На всех рисунках кривая 1 соответствует усредненной кривой гемолиза мышей группы контроля. Для мышей этой группы эритрограмма одновершинна и для нее отсутствует строгая симметричность, которая свидетельствует о некоторой гетерогенности популяции эритроцитов. Вершина эритрограммы соответствовала времени 213 с $\left(t_{1 / 2}=212,5\right.$ c, $\left.k_{t_{1 / 2}}=0,0047\right)$. Продолжительность

гемолиза составляла 455 с. Незначительное растяжение и подъем правой ветви эритрограммы указывает на присутствие в кровяном русле молодых форм эритроцитов в результате умеренного напряжения эритропоэза.

На рисунке 1 приведены эритрограммы гемолиза мышей, подвергавшихся вибрации частотой 8 Гц. В первые дни воздействия кислотные эритрограммы нефрак-

ционированных эритроцитов смещены влево относительно контрольной зависимости (зависимости 2-4). $t_{1 / 2}$ гемолиза с первого по пятый день эксперимента составило $104,4 \pm 25,5,126,1 \pm 9,3,117,6 \pm 8,7,124,1 \pm 17,7$, $138,4 \pm 22,2$ с соответственно. На эритрограммах фиксируется несколько максимумов, что указывает на усиление гетерогенности клеток, инициируемой вибрацией. На седьмой день вибрационного воздействия (рис. 1, зависимость 5) эритрограмммы характеризовались увеличенным временем гемолиза и растяжением правой ветви эритрограммы, что вероятно было вызвано увеличением количества «молодых», высокостойких к гемолизу эритроцитов в кровяном русле. При этом положение по времени максимума основного пика гемолиза практически совпало с контролем, однако он имел меньшую интенсивность $\left(_{t_{1 / 2}}=213,1 \pm 13,8 \mathrm{c}, k_{t_{1 / 2}}=\right.$ $0,0047 \pm 0,0003)$.

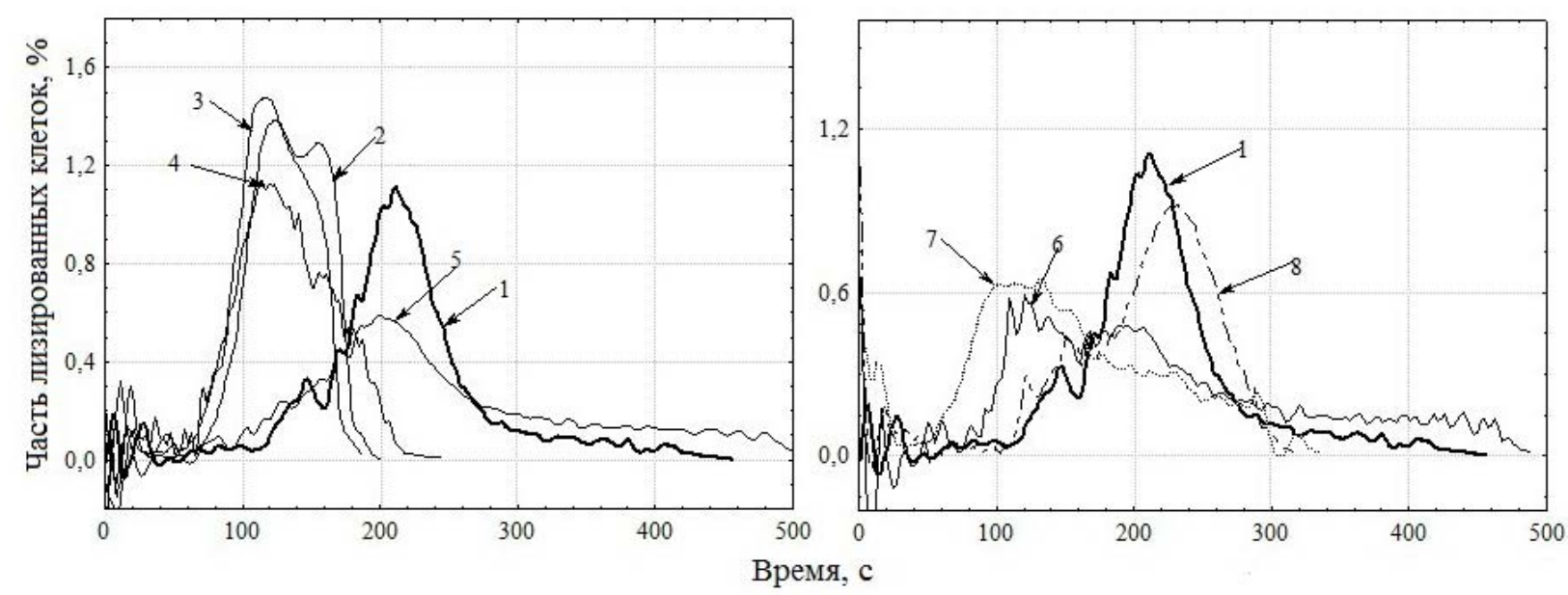

Рис. 1. Эритрограммы эритроцитов мышей, подвергавшихся вибрации частотой 8 Гц: 1 - контроль, 2 - 2-й, 3 - 3-й, 4 - 5-й, 5 - 7-й, 6 - 9-й, 7 - 11-й, 8 - 14-й дни вибрации

На девятый день воздействия регистрировали раздвоение пика эритрограмм, что свидетельствовало о наличии в кровеносном русле эритроцитов с разными свойствами биомембраны (рис. 1, зависимость 6). Видно усиление гемолиза «старых» эритроцитов (время первого интенсивного пика - 124,1 c), при этом снижение их количества на фоне молодых форм клеток привело к появлению второго пика с максимумом, соответствующим 202 с, и увеличению времени гемолиза до 490 с. На 11-й день вибрационного воздействия эритрограммы мышей снова сдвигались влево $\left(t_{1 / 2}=138,4 \pm 20,8 \mathrm{c}\right)$,

однако на 14-й день максимум эритрограммы практически совпадал с контролем.

Анализ кинетических зависимостей гемолиза (данные не приведены) показал сокращение длительности латентной фазы гемолиза для всех регистрируемых эритрограмм в течение 14 дней вибрационного воздействия. Как известно, длительность латентного периода существенно зависит от состояния белков эритроцитов, в связи с чем сокращение этой стадии указывает на нарушение межбелковых контактов и белок-липидных взаимодействий, что приводит к снижению барьера проницаемости.

На рисунке 2 приведены эритрограммы кислотного гемолиза эритроцитов мышей, подвергавшихся низкочастотной вибрации частотой 16 Гц. После однократного воздействия вибрацией регистрируемые эритрограммы практически совпадали с контролем, а на второй и третий дни эксперимента также наблюдали смещение максимумов эритрограмм влево $\left(t_{1 / 2}=117 \pm 47,7\right.$ и $120 \pm$ 41,7 c). На третий день эксперимента у некоторых животных регистрировали тенденцию к разделению эритроцитов на фракции, отличающиеся устойчивостью к гемолитическому фактору (зависимость 3). В четвертый и пятый дни эксперимента время лизиса основной фракции эритроцитов еще незначительно сокращалось (основная фракция эритроцитов лизировалась примерно за 120 с от начала реакции), однако время окончания процесса гемолиза увеличивалось на 100 с (зависимость 4). На четвертый день эксперимента отчетливо видно появление фракции эритроцитов, устойчивых к гемолизу, что было вызвано выбросом молодых эритроцитов (ретику- 
лоцитов) из костного мозга. Регистрируемая на седьмой день эритрограмма (рис. 2, зависимость 5) имела несколько максимумов: первый, с невысокой интенсивностью, регистрировали через 200 с от начала реакции, затем была видна широкая полоса, без явно выраженных максимумов, и незначительный максимум появлялся в конце процесса гемолиза через 550 с. Из эритрограмм, полученных в 9-й и 11-й дни эксперимента (рис. 2, зависимости 7,8$)$ видно, что количество фракции, лизирующейся через 120-150 с от начала реакции, возрастало, однако время окончания процесса реакции практически не сокращалось. На кинетических кривых гемолиза четко виден изгиб и уменьшение наклона завершающей части зависимости, что связано с наличием стадий, кинетически разделенных во времени и существенно различающихся по скоростям протекания (данные не показаны). На 14-й день воздействия вибрацией также видно снижение количества основной фракции эритроцитов и наличие фракции, устойчивой к гемолитическому фактору. Из анализа кривых, приведенных на рисунке 2 видно, что вибрация с частотой 16 Гц усиливает деста- билизацию мембран старых эритроцитов с последующей ликвидацией этих клеток. В ответ на действие вибрации у мышей начинаются процессы неконтролируемого эритропоэза (Minasyan et al., 2007).

На рисунке 3 приведены эритрограммы кислотного гемолиза эритроцитов мышей, подвергавшихся вибрации частотой 24 Гц. После однократного воздействия вибрацией (зависимость 2) максимум эритрограммы гемолиза смещался влево и соответствовал 166 с (в контроле -212 с). Во второй, третий и четвертый дни эксперимента наблюдали еще большее смещение максимумов эритрограмм влево относительно контроля, однако между собой эритрограммы отличались мало. Максимум эритрограмм в эти дни соответствовал в среднем $100 \mathrm{c}$, изменялась полуширина и высота эритрограмм (основной пик эритирограммы становится более узким и высоким), что указывало на преобладание во фракции «старых» эритроцитов. С пятого по седьмой дни эксперимента у животных наблюдали тенденцию к разделению эритроцитов на фракции, отличающиеся устойчивостью к гемолитическому фактору (рис. 3, зависимости 6, 7).

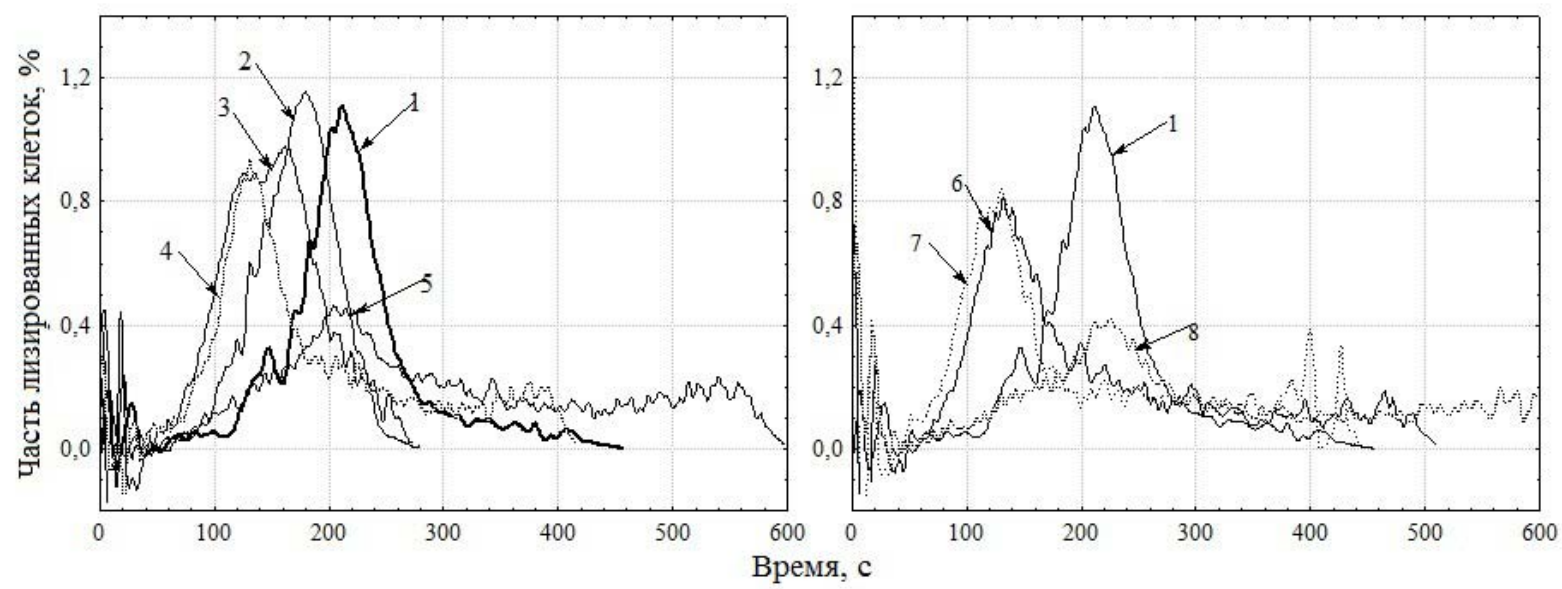

Рис. 2. Эритрограммы эритроцитов мышей, подвергавшихся вибрации частотой 16 Гц: 1 - контроль, 2 - 2-й, 3 - 3-й, 4 - 4-й, 5 - 7-й, 6 - 9-й, 7 - 11-й, 8 - 14-й дни вибрации
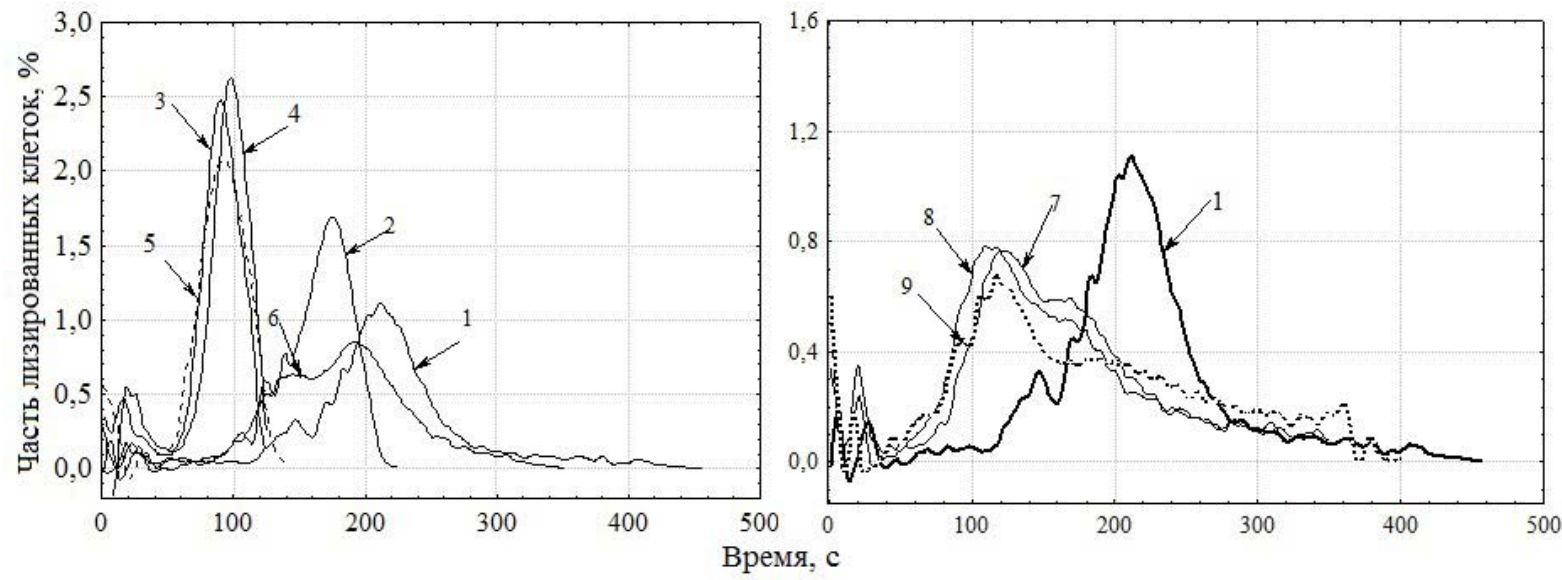

Рис. 3. Эритрограммы эритроцитов мышей, подвергавшихся вибрации частотой 24 Гц: 1 - контроль, 2 - 1-й, 3 - 2-й, 4 - 3-й, 5 - 4-й, 6 - 5-й, 7 - 9-й, 8 - 11-й, 9 - 14-й дни вибрации

Начиная с девятого дня эксперимента отчетливо видно появление фракции эритроцитов, устойчивых к гемолизу. Ширина эритрограммы увеличивалась, высота уменьшалась, на эритрограммах регистрировали несколько максимумов, и их окончание было сильно затя- нутым. На эритрограммах, полученных с 9-го по 14-й дни эксперимента (рис. 3, зависимости 8, 9), видно, что количество фракции, лизирующейся через 120-150 с от начала реакции, существенно преобладало, хотя время окончания процесса гемолиза не сокращалось. 
В отличие от кинетических кривых, регистрируемых для эритроцитов группы мышей, подвергавшихся вибрации с частотой 16 Гц, латентный период гемолиза сокращался во всех регистрируемых зависимостях, что было связано с преобладанием «старых» клеток в эритроцитарной фракции.

С первого по пятый дни воздействия с частотой 32 Гц (рис. 4) эритрограммы сдвигались влево относительно контроля, $t_{\frac{1}{2}}$ снижалось: в первый день оно со- ставило $134,1 \pm 43,5$ с, во второй $-116,6 \pm 34,7$ с, в третий $-101,9 \pm 33,2$ с, в четвертый $-89,9 \pm 21,2$ с. При этом на всех эритрограммах виден малоинтенсивный пик в области 15-20 с. Характер изменений эритрограмм свидетельствовал об увеличении количества «старых» клеток в эритроцитарном пуле. Процесс кислотного гемолиза заканчивался в среднем за 200 с (рис. 4, зависимости 2, 3, 4).



Рис. 4. Эритрограммы эритроцитов мышей, подвергавшихся вибрации частотой 32 Гц:

1 - контроль, 2 - 1-й, 3 - 3-й, 4 - 4-й, 5 - 7-й, 6 - 9-й, 7 - 11-й, 8 - 14-й дни вибрации

С пятого по 14-й дни воздействия гетерогенность эритроцитов возросла, что проявлялось в разделении основного пика гемолиза. Кроме того, возрастала интенсивность пика, соответствующего фракции эритроцитов, лизирующихся за 20 с. Второй максимум на эритрограммах появлялся через 100-120 с, что значительно меньше показателей контрольной группы. Одновременно количество «молодых» эритроцитов, наличие которых является одним из показателей интенсивности эритропоэза, снижалось. С пятого по 9-й дни эксперимента в кровотоке видимо появлялось небольшое количество молодых эритроцитов, на что указывает незначительное растяжение и подъем правой ветви эритрограммы. Как известно, следствием уменьшения или полной остановки поступления в кровяное русло «молодых» клеток является снижение кислородной емкости крови. Результатом этого является задержка в крови «старых» форм эритроцитов, что и наблюдали для мышей данной группы.

В основе патогенеза действия вибрации находится кислородное голодание тканей вследствие гиперпродукции активных форм кислорода (Kapustnik and Polyakova, 2005; Dotsenko et al., 2010). В случае кислородного голодания происходит раздражение костного мозга и в кровь поступает большое количество «молодых», возможно незрелых эритроцитов, что направлено на ликвидацию дефицита кислорода и избытка углекислого газа в организме (Haase, 2013). Таким образом, снижение количества «старых» и увеличение «молодых» эритроцитов крови экспериментальных животных является компенсаторным явлением на развитие гипоксии (Haase, 2010; Paulson et al., 2011).

Изучение системы эритрона дает возможность более объективно оценить состояние организма при действии вибрационного фактора. С этой точки зрения, вибрация в интервале частот 8-16 Гц вызывает у мышей состояние стресса, который приводит к повышению кислотной резистентости эритроцитов, что наблюдается при действии многих факторов. К типичным механизмам повышения кислотности эритроцитов можно отнести (Mikhailis, 2010): 1) разрушение наименее резистентных эритроцитов вследствие окислительной модификации белков мембраны, 2) выход менее зрелых и неповрежденных форм из депо; 3) изменения в соотношении различных фракций липидов, протеинов, полисахаридов мембран эритроцитов, приводящие к модуляции активности ферментов и их комплексов, фиксированных в мембране или связанных с ней, а также к изменению ее физико-химических свойств; 4) повышение антиоксидантной активности устойчивости эритроцитов (влияние его собственных и плазменных факторов, эритропоэтина, глюкокортикоидов); 5) стресс-стимуляция эритропоэза с образованием стресс-эритроцитов, обладающих аномально высокой резистентностью. Молодые клетки, образованные в условиях напряженного эритропоэза, являются качественно иными по сравнению с соответствующими клетками, продуцированными при нормальном кроветворении. В эритроцитах, образованных в условиях напряженного эритропоэза, ввиду ускоренной их продукции в костном мозге, а также усиленной эксплуатации после выхода в кровяное русло, быстрее, чем в эритроцитах, образованных в условиях нормального эритропоэза, наблюдается падение активности ферментов, приводящее к преждевременному старению клетки и ее элиминации из общего кровотока (Piccinini et al, 1995; Bradovich et al., 2009; Rifkind and Nagababu, 2013). 
Вибрация частотой 24, а особенно 32 Гц приводит к стресс-индуцированным нарушениям гемопоэза и клеточного состава периферической крови, которые выражаются в подавлении эритропоэза и опустошении резерва эритроцитов. Подавление стрессом эритропоэза и снижение резистентности эритроцитов приводит к гипоксии клеток и тканей, что в данных условиях является одним из механизмов стрессорных повреждений внутренних органов.

\section{Выводы}

Низкочастотная вибрация частотой 8-16 Гц амплитудой $0,8 \pm 0,12$ мм вызывает дестабилизацию мембран эритроцитов с последующей ликвидацией поврежденных клеток. Высокая активность стрессреализующих механизмов приводит к падению общего содержания эритроцитов в крови, снижению доли «старых», низкостойких эритроцитов и общему повышению устойчивости эритроцитов к кислотному гемолизу. Низкочастотная вибрация частотой 32 Гц амплитудой $0,8 \pm 0,12$ мм вызывала блокирование эритропоэза, что привело к быстрому старению эритроцитов и снижению их кислотной устойчивости.

\section{Библиографические ссылки}

Antoshina, L.I., Pavlovskaya, N.A., 2009. Biohimicheskie markery vozdejstvija vibracii na organizm rabotajushhih i ih kriterial'naja ocenka [Biochemical markers of vibration effects in workers, and their criterial evaluation]. Medicina Truda i Promyshlennaja Jekologija 12, 22-27 (in Russian).

Antoshina, L.I., Saarkoppel, L.M., Pavlovskaya, N.A., 2009. Dejstvie vibracii na biohimicheskie pokazateli, harakterizujushhie okislitel'nyj metabolizm, immunitet, obmen myshechnoj i soedinitel'noj tkanej (Obzor literatury) [Influence of vibration on biochemical values characterizing oxidative metabolism, immunity, metabolism in muscular and connective tissues (review of literature)]. Medicina Truda i Promyshlennaja Jekologija 2, 32-37 (in Russian).

Bobrova, S.V., Efremov, A.V., Vakulin, G.M., 2002. Funkcional'naja morfologija i ul'trastrukturnye izmenenija timusa pri vozdejstvii vibracii i ih korrekcija s ispol'zovaniem jessencial'nyh fosfolipidov [Functional morphology and ultrastructural changes of thymus under vibration and their correction with the help of essencial phospholipids]. Bjulleten' SO RAMN 104(2), 129-137 (in Russian).

Bodyenkova, C.M., Lizaryv, A.V., 2005. Patogeneticheskaja rol' narushenij immunoreaktivnosti organizma $\mathrm{v}$ mehanizmah vzaimosvjazi gipotalamo-gipofizarno-nadpochechnikovoj i tireoidnoj sistem pri vibracionnoj bolezni [Pathogenetic role of immune disorders in mechanisms underlying relations between hypothalamus - hypophysis - adrenals and thyroid systems in vibration disease]. Vestnik Rossijskoj AMN 3, 35 (in Russian).

Brajovich, M.L., Rucci, A., Acosta, I.L., Cotorruelo, C., Borrás, S.G., Racca, L., Biondi, C., Racca, A., 2009. Effects of aging on antioxidant response and phagocytosis in senescent erythrocytes. Immunol. Invest. 38(6), 551-559.

Damijan, Z., 2005. Changes of selected biochemical parameters of blood, densytometric and strength bones of rats under low frequency vibration. Arch. Acoust. 30(4), 495-505.

Dotsenko, O.I., Dotsenko, V.A., Mischenko, A.M., 2010 Aktivnost' superoksiddismutazy i katalazy $\mathrm{v}$ jeritrocitah i neko- toryh tkanjah myshej $\mathrm{v}$ uslovijah nizkochastotnoj vibracii [The activity of erythrocytes superoxide dismutase and catalase and some other tissues at condition of low frequency vibration]. Physics of the Alive 18(1), 107-113 (in Russian).

Dotsenko, O.I., Mischenko, A.M., 2011. Issledovanie vlijanija nizkochastotnoj vibracii na kislotnuju rezistentnost' jeritrocitov [Influence of low-frequency vibration on the erythrocytes acid resistance]. Vìsn. Dnìpropetr. Unìv. Ser. Bìol. Ekol. 19(1), 22-30 (in Russian).

Dzierzak, E., Philipsen, S., 2013. Erythropoiesis: Development and differentiation. Cold Spring Harb. Perspect. Med. 3, $1-13$.

Haase, V.H., 2010. Hypoxic regulation of erythropoiesis and iron metabolism. Am. J. Physiol. Renal Physiol. 299(1), F1-F13.

Haase, V.H., 2013. Regulation of erythropoiesis by hypoxiainducible factors. Blood Rev. 27(1), 41-53.

Heaver, C., Goonetilleke, K.S., Fetguson, H., Shiralkar, S., 2011. Handarm vibration syndrome: A common occupational hazard in industrialized countries. J. Hand Surg. Eur. Vol. 36(5), 354-363.

Hughes, J.M., Wirth, O., Krajnak, K., Miller, R., Flavahan, S., Berkowitz, D.E., Welcome, D., Flavahan, N.A., 2009. Increased oxidant activity mediates vascular dysfunction in vibration injury. J. Pharmacol. Exp. Ther. 328(1), 223-230.

Kapustnik, V.A., Polyakova, L.A., 2005. Oksidantnyj stress pri hronicheskom vozdejstvii jenergomehanicheskih kolebatel'nyh dvizhenij v proizvodstvennyh uslovijah: profilaktika i reabilitacija [Oxidative stress under chronic effect of power-mechanical oscillatory motions in working conditions: prevention and rehabilitation]. Likars'ka Sprava 7, 75-79 (in Russian).

Krajnak, K., Riley, D.A., Wu, J., McDowell, T., Welcome, D.E., Xu, X.S, Dong, R.G., 2012. Frequency-dependent effects of vibration on physiological systems: Experiments with animals and other human surrogates. Ind. Health 50(5), 343-353.

Leonova, V.G., 1987. Analiz jeritrocitarnyh populjacij v ontogeneze cheloveka. Nauka, Novosibirsk (in Russian).

Mikhailis, A.A., 2009. Stress-inducirovannaja dinamika gemoliticheskoj stojkosti jeritrocitov pri razlichnyh vidah povrezhdajushhih vozdejstvij [Stress-induced dynamics of erythrocytes hemolytic resistance at various types of injury]. Vestnik Rossijskogo Universiteta Druzhby Narodov. Serija: Medicina 4, 96-100 (in Russian).

Mikhailis, A.A., 2010. Konceptual'naja model' stressintucirovannoj dinamiki kislotno-gemoliticheskoj stojkosti jeritrocitov [Conceptual model a stress-induced dynamics of erythrocytes acid-hemolytic resistance]. Sovremennye Naukoemkie Tehnologii 10, 19-23 (in Russian).

Minasyan, S.M., Adamyan, T.I., Gevorkyan, E.S., 2007. Izmenenie morfologicheskih pokazatelej krovi v dinamike vozdejstvija vibracii i kornej solodki [Changes of morphological indicators of blood from vibration and liquorice effect]. Russ. J. Physiol. 93(3), 1035-1042 (in Russian).

Pattnaik, S., Banerjee, R., Kim, J., 2012. Spatial resonance in a small artery excited by vibration input as a possible mechanism to cause handarm vascular disorders. J. Sound Vibration 331(8), 1951-1960.

Paulson, R.F., Shi, L., Wu, D., 2011. Stress erythropoiesis: New signals and new stress progenitor cells. Curr. Opin. Hematol. 18(3), 139-145.

Piccinini, G., Minetti, G., Balduini, C., Brovelli, A., 1995. Oxidation state of glutathione and membrane proteins in human red cells of different age. Mech. Ageing Dev. 78(1), 15-26.

Rifkind, J.M., Nagababu, E., 2013. Hemoglobin redox reactions and red blood cell aging. Antioxid. Redox Signal. 18(17), $2274-2283$. 
Sauni, R., Pääkkönen, R., Virtema, P., Toppila, E., Uitti, J., 2009. Dose-response relationship between exposure to handarm vibration and health effects among metalworkers. Ann. Occup. Hyg. 53(1), 55-62.

Stoyneva, Z.B., Dermendjiev, S.M., 2010. Specific features of vibration-induced disorders. Folia Med. (Plovdiv) 52(4), $27-31$.

Vemula, S., Shi, J., Mali, R.S., Ma, P., Liu, Y., Hanneman, P., Koehler, K.R., Hashino, E., Wei, L., Kapur R., 2012. ROCK1 functions as a critical regulator of stress erythropoiesis and survival by regulating p53. Blood 120(14), $2868-2878$

Vorobieva, V.V., Shabanov, P.D., 2010. Blokatory medlennyh kal'cievyh kanalov 1-tipa podderzhivajut jenergeticheskij obmen v kardiomiocitah krolika pri vozdejstvii obshhej vibracii [The blockers of l-type calcium channel support en- ergy metabolism in rabbit cardiomyocytes in exposure of general vibration]. Russ. J. Physiol. 96(6), 573-581 (in Russian).

Vorobieva, V.V., Shabanov, P.D., 2012. Stressirujushhee vozdejstvie lokal'noj vibracii na jenergeticheskij obmen serdca, pecheni i pochki krys [Stressogenic exposure of local vibration to energetic metabolism of the heart, liver and kidney of rats]. Russ. J. Physiol. 98(2), 293-299(in Russian).

Ziegler, S., Zöch, C., Gschwandtner, M., Eckhardt, G., Windberger, U., Minar, E., Rüdiger, H., Osterode, W., 2005. Thermoregulation and rheological properties of blood in primary Raynaud's phenomenon and the vibration-induced white-finger syndrome. Int. Arch. Occup. Environ. Health 78(3), 218-222.

Надійшла до редколегії 21.04.2014 